\title{
On Translation Methods of Materialogy English
}

\author{
Liang $\mathrm{Ma}^{1}$ and Wei Zhao ${ }^{2}$ \\ ${ }^{1}$ Foreign Language Department, 150080 Harbin University of Science and Technology, China \\ ${ }^{2}$ Architechture Engineering Department, 150080 Heilongjiang Polytechnic, China
}

\begin{abstract}
There are various common problems in the translation of materialogy English, which are caused by a lot of specific English language features of materialogy. Therefore the staffs of materialogy should learn these features as well as learn some basic translation skills in order to introduce more western technique of materialogy to China. A lot of practical examples are quoted here to enhance the understanding on the translation methods of materialogy English.
\end{abstract}

Keywords: translation method, Materialogy English, word translation, sentence translation, translation skills.

\section{Introduction}

Chinese and English belong to the distinct families of language so there are a large number of distinctions in the language structure, ways of expression and modes of thinking, which lead to a great deal of translation mistakes. Many features of materialogy English and some basic translation skills are introduced here, which are of great importance for the staffs of the materialogy.

\section{Feature of the materialogy English words and the translation skills}

\subsection{Compound words}

There are a great number of compound words which are made of two or more words in a logical order in materialogy English. For example: Themodynamics, Intemetallics, Semiconductor, Stereoselectivity, Ferromagnetism, Nanocomposite, Biomaterial.

\subsection{Abbreviations}

Abbreviation, a new trend of the modern materialogy English meets its needs that the time and space should be saved. Abbreviations are very common in materialogy English. It could be divided into two categories. The first kind is the ones used as materialogy terms while the other kind is the ones used in materialogy article.

\subsubsection{Abbreviation used as terms in materialogy English}

The first letter of each word will remain to form a new abbreviatioin with all letters capitalized or not. For example CMS is short for computational materials science. APF is short for atomic packing factor. RE is short for rare earth. DOS is short for density of states. TEM is short for transmission electronmicroscope. For these abbreviations the translator must understand what each letter represents for then the meaning of these abbreviations can come to you.

\subsubsection{Abbreviation often used in materialogy English}

There are a lot of daily abbreviations which are often used in materialogy English. In fact most of these come from Latin words. For example VS is short for versus. The word i.e. is short for idest. lb is short for libra.

\subsection{Prefix and suffix}

There are a large number of materialogy English words which include prefix, root and suffix of Latin or Greek, which is a feature of materialogy English words. It would be useful for us to read and translate the English books and journals of materialogy that we understand these prefixes and suffixes. A study shows that there are $46 \%$ words from Latin and $7.2 \%$ ones from Greek in ten thousands common English words while this percentage is higher in the technological words. [1]

The most common prefixes and suffixes are about one hundred which owns the specific meaning. The words formed by these prefixes and suffixes are always nouns which are usually used for definition of 
the product. Therefore it is of great importance for us to learn the prefixes and suffixes as many as possible in order to enlarge our vocabulary which is helpful for the translation of the materialogy English.

\subsection{Word class shift}

The class of various English words needs to be shifted in order to be understood by the Chinese. For example:

Precipitation hardening or aging hardening is one of the most widely adopted techniques for strengthening of structural materials.

In this sentence the phrase "strengthening of structural materials" need to be translated into a verb phrase in Chinese instead of noun phrase in original English in order to be more concise and more Chinese.

From the analysis above word class shift is of great use for the understanding of lots of English text in materialogy. Apart from word class shift mentioned above there are some other kinds of word class shift such as prep translated as verb, adj. translated as verb or noun and so on.

\section{Features of the materialogy English sentences and the translation skills}

\subsection{Shift of the word sequence}

The The word sequence is always changed, especially in passive voice, in the translation. The object, phenomenon and the process, not the people, are always the focus of the research. Therefore these research objects are always in the position of subject in order to attract the reader' s attention. While people are always in the position of subject in Chinese so the word order needs to be changed in the translation.

For example:

Magnesium and its alloys have been extensively used in aircraft industry vehicle production and portable electronic devices.

In this sentence the word magnesium and its alloys are shifted to the position after the word used. The passive voice in English is changed into the active voice in Chinese in the translation in order to be more Chinese.

\subsection{Attributive clause translations}

Attributive clause is the most complex one in English subordinate clause so it's very difficult to be translated. There are lots of attributive clauses, just like passive clauses, in the materialogy English because of its clear structure and being logical. The attributive clause is always used to modify the noun, pronoun or other words with the function of noun to convey the clear meaning of the word of being modified. Apart from the complex structure and various implications it is often used to convey the meaning of supplement, transition, cause and effect, purpose, condition and concession so it could be translated by different methods according to its structure and implication. Here a common method, dividing translation, is introduced to translate the attributive clause. Dividing translation is that the sentence is divided into two or more sentences in the translation. For example:

Magnesium is a silvery - white and light weight metal which tarnishes slightly when exposed to air although unlike the alkaline metals storage in an oxygen-free environment is unnecessary because magnesium is protected by a thing layer of oxide which is fairly impermeable and hard to remove.

This complex sentence is needed to be divided and the attributive clause - which tarnishes slightly when exposed to air although unlike the alkaline metals storage in an oxygen-free environment is unnecessary because magnesium is protected by a thing layer of oxide which is fairly impermeable and hard to remove- needs to be translated into an independent sentence in order to be understood by Chinese reader. 


\subsection{Common sentence structures in materialogy English}

There are several common sentence structures with different stylistic features in materialogy English such as the structure of "It... that...", participle phrase structure and elliptical sentence structure. For example:

It has recently been shown that $\mathrm{Zn}$ can enhance the grain in refinement effects of $\mathrm{Zr}$ in the $\mathrm{Mg}-\mathrm{Zn}-\mathrm{Zr}$ system up to certain concentration beyond which the enhancement starts to decrease.

In this sentence the phrase structural "It's ...that..." is used to show the meaning of being objective and the conclusion is drawn without the interference of the people. But when the sentence is translated into Chinese the subject of "it" should be change into the person according to the Chinese tradition in which people are the focus.lace the figure as close as possible after the point where it is first referenced in the text. If there is a large number of figures and tables it might be necessary to place some before their text citation.

\section{Conclusion}

The translation of materialogy English is a large and complex project. We could draw the conclusion that the characteristics of materialogy English is of great importance for the staffs of materialogy. They should learn these features and apply them into the Chinese to English translation. Apart from that the staffs also should enlarge knowledge of their domain and gather experiences. Only in this way can they be more skilled and the translation can be more accurate.

\section{References}

[1] Qingjia Yan, Wenpei Yan: English Translation of science and technology method. (Metallurgical Industry Press, Beijing 1992).

[2] Ronggui Mao: A Course in Chinese-English Translation in New Century. (Jiao Tong University Press, Shanghai 2005).

[3] Quanshui Wang: The Discussion of the science and technology translation (Chinese Science \& Technology Translators, China1998).

[4] Peiji Zhang, Yungen Yu and so on: A course in English-Chinese translation. (Shanghai Foreign Language Education Press, Shanghai).

[5] Qiuming Li: Reading and Translation. (Dalian Science and technology University Press, Liaoning 1997).

[6] Gaosheng Wang: The Writing of the Abstract and Its Translation into English. (Chinese Science \& Technology Translators, China 2000).

[7] Jianping Yu: The Analysis and Translation of the long sentence in Science and Technology English. (Chinese Science \& Technology Translators, China 2000).

[8] Shimei Feng, Yaowen Du: The Modern Technology English words and their translation. (Chinese Science \& Technology Translators, China 2000). Jianping Yu: The Analysis and Translation of the long sentence in Science and Technology English. (Chinese Science \& Technology Translators, China 2000).

[9] Jianzhong Guo: The Translatioin of Popular Science and Science fiction. (China Translation and Publishing Corporation, China 2004).

[10] Zhijie Feng: The Chinese to English Science and Technology Translation. (China Translation and Publishing Corporation, China 1998). 